\title{
A Justiça Consensual do Tribunal Múltiplas Portas e a Política Pública Norte-Americana de Tratamento de Conflitos: Contribuiçóes aO MODELO BRASILEIRO
}

Charlise Paula Colet Gimenez*

1 Considerações iniciais. 2 A organização judiciária norte-americana no sistema jurídico do common law: o desenvolvimento das práticas de alternative dispute resolution (ADR). $3 \mathrm{O}$ tratamento do conflito pelo multidoor courthouse system. 4 Considerações finais. Referências.

\section{RESUMO}

O presente artigo tem como tema a justiça consensual e o tratamento de conflitos, cuja delimitação está em estudar o modelo do Tribunal Múltiplas Portas, dos Estados Unidos da América, para possíveis contribuições à política judiciária brasileira - Resolução no 125 de 29 de novembro de 2010, do Conselho Nacional de Justiça brasileiro. O estudo, a partir do método de abordagem hipotético-dedutivo e do método de procedimento bibliográfico, merece uma análise aprofundada diante da dificuldade dos mecanismos tradicionais adotados pelo Poder Judiciário em atender satisfatoriamente a todos os conflitos submetidos ao seu julgamento, bem como pelos entraves verificados na concretização dos métodos autocompositivos no Brasil. Por outro lado, a experiência nos Estados Unidos da América, a qual estuda meios complementares de tratamento de conflitos desde os anos de 1920, reconhece uma postura dicotômica, com a qual as próprias partes constroem suas respostas, considerando suas necessidades, seus interesses e a relação entre elas. Desse modo, considerando as características do conflito, o multiportas apresenta o método mais adequado, o que garante a satisfação de todos os envolvidos. Nesse sentido, garante o acesso à justiça no sentido amplo e fortalece a participação social do cidadão, fomentando uma cultura de paz, de alteridade e de tratamento de conflitos de forma qualitativa, adequado às características de cada pessoa e à tipologia do conflito.

Palavras-chave: Tratamento do conflito. Justiça Consensual. Tribunal Múltiplas Portas. Cultura de Paz.

* Doutora em Direito pela Universidade de Santa Cruz do Sul - UNISC. Professora dos Cursos de Graduação, Mestrado e Doutorado em Direito da Universidade Regional Integrada do Alto Uruguai e das Missões URI, campus Santo Ângelo/RS. Coordenadora do Curso de Graduação em Direito da URI, campus Santo Ângelo/RS. E-mail: <charliseg@santoangelo.uri.br>. 


\section{CONSIDERAÇÕES INICIAIS}

Nos Estados Unidos da América, a abordagem de práticas complementares para o adequado tratamento do conflito pelo Tribunal Múltiplas Portas iniciou em 1976, a partir da Conferência Pound, em homenagem ao professor Roscoe Pound, cujo objetivo era refletir acerca das causas da insatisfação no sistema judicial norte-americano. Para Pound, o qual discutia as dificuldades encontradas pela administração da justiça, havia a possibilidade de lançar um olhar otimista para o Direito, diante do cenário na época, por meio de ideias e teorias de outras disciplinas. Assim, a análise multidisciplinar, envolvendo Economia, Ciência Política, Filosofia, Psicologia, Sociologia e Religião na produção do Direito, permitiu um novo Direito adaptado a um mundo moderno e complexo. ${ }^{1}$

Nesse rumo, o professor da Escola de Direito da Universidade de Harvard, Frank Sander, desenvolveu o conceito do multidoor courthouse system, sob a justificativa de que o tratamento adequado ao conflito permite o uso eficiente dos recursos pelos tribunais; acarreta a redução de custos e de tempo pelas partes e pelo próprio Poder Judiciário; e diminui o número de conflitos subsequentes. Na época em que Sander apresentou sua proposta, não havia no país nenhum centro de tratamento de conflitos, registro de advogado aconselhando por meio de petição o uso de métodos complementares ou, ainda, autorização explícita dos tribunais para o seu uso.

Em 2003, havia 35 estados norte-americanos com centros de tratamento de conflitos, um grande número de petições de advogados aconselhando o encaminhamento do processo para um tratamento do conflito diverso da adjudicação e autorizações expressas do Poder Judiciário para a adoção de tais métodos. Ademais, estimou-se que em 2001, na Flórida, estado que utiliza as práticas de tratamento de conflitos no mais alto grau do Poder Judiciário, foram 113.000 processos encaminhados para os métodos complementares. ${ }^{2}$

Destaca-se que, a partir da Conferência de 1976, criou-se a Divisão de Melhoramentos na Administração da Justiça, com uma força-tarefa para avaliar e implementar as ideias lançadas no encontro, incorporada, também, pela American Bar Association (ABA) ${ }^{3}$, inclusive com leis estaduais e federal sobre o tema, como o dever ético do advogado de avaliar diferentes formas de resolução de conflitos em suas ações. ${ }^{4}$

O professor, ao apresentar o Tribunal Múltiplas Portas, questionou "what are the significant characteristics of various alternative dispute resolution mechanims (such as adjudication by courts, arbitration, mediation, negotiation, and various blends of these and other devices)?"5 bem como perguntou "how can these characteristics be utilized so that, given the variety of disputes that presently arise, we can begin to develop some rational criteria for allocating various types of disputes to different resolution processes?". ${ }^{6}$ A consequência das respostas às perguntas anteriores é o melhor ajuste no encaminhamento de casos para a adjudicação e casos para os demais métodos complementares de tratamento de conflitos. ${ }^{7}$ 
A questão fundamental, portanto, centra-se em examinar as diferentes formas de resolução de conflitos e responder quais portas seriam adequadas em relação a quais conflitos. ${ }^{8}$ A importância da presente discussão reside em escolher a ferramenta/método mais eficaz para a disputa, a qual dará aos conflitantes a maior satisfação aos seus interesses. Em segundo lugar, importa em convencer o oponente acerca das vantagens em adotar formas complementares mais específicas ao conflito em si; e, em terceiro, em convencer o tribunal do porquê da escolha de uma porta em detrimento de outra, ou vice-versa. ${ }^{9}$

Nesse sentido, o artigo ora apresentado tem por objetivo estudar a política pública norte-americana de tratamento de conflitos no sistema do common law, apresentando os seus mecanismos aplicáveis à solução dos litígios, analisando as contribuições do modelo norte-americano do Tribunal Múltiplas Portas à política judiciária brasileira ${ }^{10}$ - Resolução n. 125 do Conselho Nacional de Justiça, de 29 de novembro de $2010^{11}$, a qual instituiu no Brasil uma política de tratamento de conflitos, apresentando a mediação e a conciliação como as formas autocompositivas, e determinando aos Tribunais a criação e a gestão de centros judiciários de resolução de conflitos e a capacitação do terceiro facilitador.

\section{A ORGANIZAÇÃO JUDICIÁRIA NORTE-AMERICANA NO SISTEMA JURÍDICO DO COMMON LAW: O DESENVOLVIMENTO DAS PRÁTI- CAS DE ALTERNATIVE DISPUTE RESOLUTION (ADR)}

O sistema jurídico norte-americano pode ser classificado como common law $w^{12}$ misto, pois apresenta um valor vinculante de uma regra definida por um acórdão de um Tribunal superior, considerada com efeitos universais, além das partes no processo sub judice, ao lado da existência de normas escritas por legisladores postados fora de atividade judicante, eventualmente com hierarquia superior àquelas definidas por aqueles órgãos - e apresenta características especiais em razão de ser uma federação com grande autonomia dos Estados, em termos de direito material e processual.

Por sua vez, a organização judiciária do país é regulada nos níveis federal e estadual, a partir do sistema político acima indicado, o qual é adotado nos EUA. A norma que instituiu o país - a US Constitution - somente previu a Supreme Court, ${ }^{13}$ deixando a organização e as regras da Corte para US Statutes. ${ }^{14}$ A Constituição Federal dos EUA, com suas emendas, denominada de Bill of Rights, foi aprovada em 25 de setembro de 1789, e ratificada pelos estados em 15 de dezembro de 1791. O seu artigo III, seção ${ }^{15}$, estabelece que o Poder Judiciário dos EUA será investido em uma Suprema Corte e os tribunais inferiores estabelecidos oportunamente pelo Congresso. Os juízes conservarão os seus cargos enquanto servirem bem, percebendo remuneração protegida de qualquer redução durante o exercício da atividade.

A seção $2^{16}$ determina que a competência do Poder Judiciário se estenderá a todos os casos de aplicação da lei e da equidade ocorridos diante da Constituição, das leis dos Estados 
Unidos e dos tratados concluídos ou que forem concluídos sob sua autoridade; a todos os casos que afetem os embaixadores, ministros e consules; às questões do almirantado e de jurisdição marítima; às controvérsias em que os Estados Unidos sejam parte, ou entre dois ou mais estados, entre um estado e cidadãos de outro estado, entre cidadãos de diferentes estados, entre cidadãos do mesmo estado reivindicando terras por concessões feitas por outros estados; enfim, entre um estado, ou os seus cidadãos, e potências, cidadãos, ou súditos estrangeiros.

Os poderes não delegados aos EUA pela Constituição, nem por ela negados aos estados, são reservados aos estados-membros ou ao povo. Assim, a justiça nos estados da Federação é regida pelas Constituições estaduais, pelos State statutes e pelas regras votadas em seus Judiciários superiores. Destaca-se que a matéria não é de competência remanescente e a legislação federal não pode interferir na soberania estadual. ${ }^{17}$

Na justiça federal, o sistema é regulado pelas Federal Rules of Civil Procedures, editadas pela Suprema Corte, em 1938. Pela competência em razão da matéria, essa área compreende: a) a questão federal (federal question cases); b) causas baseadas em diversity cases; e c) competência fundamentada nas modificações da competência original. Os federal question cases envolvem: 1) a interpretação e a aplicação da Constituição Federal, inclusive com o julgamento de habeas corpus; 2) a interpretação e a aplicação de atos internacionais; 3) os casos em que há atribuições exclusivas às cortes federais pelas leis federais, em geral, em diplomas que regulam direito material, como falência e concordata; patentes e direito autoral, etc. Por sua vez, nos diversity cases, a justiça federal se apresenta como um foro neutro para abordar a diversidade de "cidadanias".

Assim, nessa seara, há três graus. O primeiro com competência originária e os demais com competência originária restrita e competência recursal. Em primeiro grau, estão os US District Courts, totalizando 94 em todo o país, com jurisdições que devem corresponder aos limites territoriais dos estados-membros. Elas são constituídas de um juiz, cuja decisão é singular, ou decisões de júri. Há, também, previsões para tribunais com três juízes, em casos determinados por lei.

Ainda, no primeiro grau, há cortes com competência especial: a) Court of Claims, competente para julgamento originário de casos em que os EUA figuram no polo passivo; b) Court of Customs and Patent Appeals, para julgamentos de pedidos judiciários de recursos de decisões administrativas do Patent Office sobre pedidos de registros de patentes e direitos assemelhados; c) Customs Court, de conhecimento e julgamento de pedido de exame judicial das decisões administrativas da International Trade Commission; d) Courts of Military Appeals, de exame judicial das decisões das cortes disciplinares das Forças Armadas na aplicação das regras militares.

Salienta-se que, exceto casos tributários e de Direito disciplinar aos militares, no Direito norte-americano, não há organização judiciária para assuntos especializados. Portanto, 
não há justiça do trabalho, nem eleitoral, nem militar, sendo a única divisão conhecida a da Justiça Federal e a justiça entre os estados-membros.

A seu turno, o segundo grau da Justiça Federal norte-americana compõe-se por 13 tribunais regionais, sendo um para o District of Columbia ${ }^{18}$ (sediado na cidade de Washington, capital do país), um de competência limitada (Court of Appeals for the Federal Circuit) e 11 tribunais regionais (US Court of Appeals for the Circuit). E, por sua vez, o terceiro grau, de jurisdição nacional, é a US Supreme Court, composta por 8 Ministros (Associate Justices) e um Presidente (Chief Justice), o qual dá seu nome para o período de sua gestão.

A organização da justiça nos estados-membros, em razão do modelo de federação vigente no país, consagrando uma impressionante autonomia a eles, varia de estado para estado, motivo pelo qual algumas apresentam três graus e outras, por outro lado, dois. Em primeiro grau, encontram-se os juízes singulares, os quais decidem com ou sem a participação do júri, exceto quando houver justiça especializada. Como exemplo, tem-se o estado de Nova Iorque, cuja organização judiciária de primeiro grau apresenta-se da seguinte forma: Supreme Courts (jurisdição cível e criminal, com competência geral) e as courts of limited jurisdiction: Family and Domestic Relations Courts (para relações de Direito de Família e no âmbito doméstico), Probate Courts (para inventários), Surrogate's Courts (para órfãos e sucessões) e outros órgãos, cujas decisões são sempre rejulgadas pelos tribunais/foros de competência geral: Police Courts (para infrações de trânsito, reclamações entre vizinhos, etc.); Small Claims Courts (estrutura e competência semelhante ao Juizado Especial Cível, no Brasil); e Tariffs Courts (para tributos estaduais em revisão de decisões administrativas).

Em segundo grau, encontram-se as cortes colegiadas, com composição e matéria de julgamento de acordo com cada estado. No estado de Nova Iorque, conforme exemplo, denominam-se Appellate Division of the Supreme Court. A nomenclatura, na maioria dos estados, é Courts of Appeal. Já em sede de terceiro grau, os estados possuem, de forma colegiada, as cortes, cujo nome revela o estado a qual pertencem, por exemplo, no estado de Nova Iorque: New York Court of Appeals. ${ }^{19}$ Importante, também, enfatizar a existência nos Estados Unidos da América dos tribunais administrativos, com função de dirimir conflitos entre os administrados e os órgãos da Administração descentralizada.

O crescente número de conflitos judicializados nos tribunais/foros dos Estados Unidos da América, somados com o tempo e o custo do processo, provocaram o debate e a reflexão entre os magistrados, serventuários da justiça e advogados de medidas para tornar eficiente a administração da resposta processual. Nessa ótica, iniciou-se o processo de reconhecimento e expansão territorial e técnica dos métodos complementares de tratamento de conflitos, marcando fortemente as décadas de 1970, 1980 e 1990 nos Estados Unidos da América. 20

Na primeira, conforme referido no intróito deste artigo, a Conferência Pound de 1976, que reuniu juristas e advogados preocupados com os custos e o tempo do acesso ao Judiciário, é 
considerada o marco do debate, da qual decorreram investimentos públicos em projetos piloto de mediação e arbitragem, apoiado pela Associação dos Advogados ao sistema multiportas.

Posteriormente, em 1980, observa-se a advocacia aproximando-se dos métodos de tratamento de conflitos, bem como a indústria de seguros realizando pesquisas para reduzir os custos de litigância para as partes, influenciando na institucionalização de práticas complementares aos litígios na área dos negócios. Ao final de 1990, a experimentação e os projetos piloto deram espaço para a efetiva institucionalização das práticas de ADR, em especial, no Poder Judiciário. As cortes estaduais também sofreram a influência, oferecendo o serviço, e as próprias pessoas passaram a solicitar a seus advogados as práticas complementares para o seu litígio.

Em 1991, a Escola de Direito de Harvard, com a ABA e The Center for Public Resource (CPR) Legal Program, organizou a National Conference on Emerging ADR issues in the State and Federal Courts, para relatar experiências em meios complementares de tratamento de conflitos vivenciadas até aquele momento pelo Poder Judiciário norte-americano. Esse evento foi realizado na sequência da promulgação do Civil Justice Reform Act (1990) ${ }^{21}$, o qual estabelecia que todas as cortes federais no país implementassem planos de redução de custos e de morosidade na prestação jurisdicional, incluindo a consideração das práticas ADR. ${ }^{22}$

Destaca-se, ainda, no ano de 1998, o Alternative Dispute Resolution Act ${ }^{23}$, o qual determinou a adoção dos mecanismos alternativos de resolução de disputas pelos tribunais federais em todas as ações cíveis. Assim, todo tribunal deve, de forma obrigatória, oferecer às partes, no mínimo, um mecanismo de tratamento de conflito, o qual deve ser analisado por elas, embora não sejam obrigadas a participar.

Ademais, cada tribunal deve ter um funcionário encarregado de divulgar os métodos complementares, recrutando e treinando os terceiros neutros que atuarão enquanto facilitadores. Em agosto de 2001, a ABA e a National Conference of Comissioners on Uniform State Laws, publicaram o Uniform Mediation Act (UMA), com o objetivo de dar um tratamento nacional à matéria e difundir a mediação, razão pela qual o documento substituiu as normas estaduais de mediação existentes nos Estados Unidos e regulamentou, de forma uniforme, os métodos consensuais de tratamento de conflitos. ${ }^{24}$

O UMA contém regras sobre a mediação abordados em mais de 2.500 estatutos estaduais e federais, e mais de 250 delas lidam com questões de confidencialidade e privilégios. Complexidade significa incerteza, o que pode inibir a utilização da mediação. Assim, o documento oferece uma única lei abrangente que rege privilégios e confidencialidade na mediação. Igualmente, um dos objetivos centrais da UMA é dar prioridade ao procedimento da mediação para garantir a confidencialidade, estabelecendo-a para os mediadores e mediandos ao proibi-los de utilizar o que foi mencionado na sessão em um processo judicial posteriormente. A lei também prevê exceções importantes para a confidencialidade. 
Tais exceções incluem: ameaças feitas para infligir danos corporais ou outros crimes violentos; tentativa das partes de recorrer à mediação para planejar ou cometer um crime; a necessidade de informação para provar ou refutar as alegações de abuso infantil ou negligência; ou a necessidade de informação para provar ou refutar uma reclamação ou queixa de falta profissional por um mediador. Como proteção dos envolvidos, em caso de má-prática do mediador, ou conflito de interesse, ele é descredenciado, sendo substituído por outro. Ainda estabelece a autonomia das partes na construção do acordo, bem como não permite o uso da mediação para processos coletivos de relações de trabalho, conferências de liquidação judicial e processos em que as partes sejam todas menores de idade.

Defende-se que a uniformidade da lei traz ordem e compreensão para fora do estado. Sem uniformidade, não pode haver nenhuma garantia firme em qualquer estado que a mediação é privilegiada. ${ }^{25} \mathrm{~A}$ adoção e a implementação das normas acima descritas pelos estados norte-americanos, no ano de 2016, atingiu 13 estados.

Há muitas fontes de regulação das práticas complementares como jurisprudência, estatutos, leis e regras locais, tanto em nível federal e estadual, mas ainda permanecem na esfera privada, nos EUA, as práticas de $\mathrm{ADR}$, devendo as partes optar contratualmente antes, durante ou depois do conflito, a forma de gerir os seus litígios. Ou seja, não há nenhuma exigência formal de comunicação de tais processos ou os seus resultados, permanecendo desconhecidas as dimensões reais de resolução de litígios privados, muitas vezes, totalmente aprovados e sancionados por instituições públicas.

Por isso, afirma-se que os EUA revelam, atualmente, um novo cenário: "dispute resolution in the US is now formal, informal and 'semi-formal". ${ }^{26} 27$ Por isso, a autora afirma que "the question here is whether 'semi-formal' processes can legitimately operate in a space between the transparency and presumed consistency of formal justice, and the confidentiality, flexibility and self-determination of informal processes". ${ }^{28} 29$

A justiça formal caracteriza-se pela transparência e pela publicidade do processo, baseada em argumentos a partir de precedentes legais e provas, incluindo apresentação de documentos e oitiva de testemunhas, a partir dos quais é tomada uma decisão por um terceiro juiz (ou júri), podendo ela ser revista em uma instância superior. A seu turno, a justiça informal foca em métodos consensuais, confidenciais e mais responsivos, constituindo-se em formas privadas de tratamento de conflitos como negociação, mediação e outros.

Nesse contexto, o sucesso relativo dos métodos consensuais provocou a sua adaptação e transformação de procedimentos informais privados para uso no setor público, inclusive como etapa obrigatória nos processos (condição para o acesso ao processo público e formal). Como visto, em decorrência da expansão e da aceitação da justiça informal e consensual de tratamento de conflitos, os tribunais/foros, em todos os graus, federal e estadual, passaram a oferecer, inicialmente de forma voluntária, e posteriormente obrigatória, programas de mediação e arbitragem, incluindo mais tarde outros métodos que foram desenvolvidos. Alguns 
magistrados, de forma inovadora, adaptaram as técnicas dos procedimentos informais para processos da área pública.

Desse modo, consoante afirma Menkel-Meadow ${ }^{30}$, por força de legislação federal, a Civil Justice Reform Act de 1990 e a Alternative Resolution Dispute Act (1998), praticamente todos os Tribunais federais dos EUA possuem algum método complementar de tratamento de conflito. Os relatórios estatísticos disponibilizados por alguns estados mais populosos (incluindo Nova Iorque, Califórnia, Texas e Michigan) demonstram o alto uso de uma variedade de formas de resolução de litígios, dentro do tribunal formal, com ‘taxas de liquidação' variando de 30 por cento para mais de 70 por cento em alguns tribunais. Praticamente todos os tribunais federais de apelação agora têm programas formais de mediação, a maioria com equipes de funcionários em tempo integral, alguns contando com voluntários.

Nesse contexto, insere-se, na seção seguinte, o sistema multiportas, cujo objeto não se destina apenas à redução de custo e tempo dos processos judiciais, mas a criar uma taxonomia que apresente a porta mais apropriada para cada tipo de conflito, considerando as pessoas nele envolvidas e a satisfação de suas necessidades, razão pela qual sua análise tem por escopo observar possíveis contribuições ao modelo brasileiro de política judiciária de tratamento de conflitos.

\section{O TRATAMENTO DO CONFLITO PELO MULTIDOOR COURTHOUSE SYSTEM}

Originalmente denominado de Comprehensive Justice Center, ${ }^{31}$ o Multidoor Courthouse System recebeu essa denominação pela ABA após ter sido quase que acidentalmente criado pelo professor da Universidade de Harvard, Frank Sander. O autor relata que compilou suas anotações acerca de suas reflexões relacionadas às insatisfações referentes às Varas de Família para a resolução de disputas nessa área, bem como pelos avanços verificados na arbitragem para os litígios trabalhistas, enviando-as aos seus colegas da Universidade de Harvard para comentários.

Porém, sem seu conhecimento, um deles encaminhou a outro colega da Universidade da Pensilvânia que, por sua vez, estava trabalhando com Warren Burger (Justice Chief - Presidente da Supreme Court), que estavam, em conjunto, planejando uma Conferência (1976) em homenagem ao professor Roscoe Pound, que anteriormente já havia debatido acerca da problemática da Justiça. O propósito era promover o debate sobre vários assuntos relacionados à insatisfação com o sistema de administração da Justiça, dentre eles, a resolução de disputas. Em vista disso, Sander foi convidado ${ }^{32}$ para apresentar sua proposta. ${ }^{33}$

Nessa oportunidade, o professor da Harvard Law School manifestou ${ }^{34}$ que o ser humano está acostumado a buscar a satisfação do seu conflito tradicionalmente no Poder Judiciário, negligenciando que a adjudicação não pode ser a resposta para todos os litígios. $\mathrm{O}$ papel 
dos advogados foi muito destacado, e a sua organização financiou projetos-piloto do sistema multiportas no Judiciário norte-americano. ${ }^{3536}$ Nesse contexto, o Multidoor Courthouse System apresenta-se como instrumento de tratamento de conflitos a fim de encaminhar a demanda a uma abordagem mais adequada, considerando as suas peculiaridades.

Assim, a recomendação de Sander consistia na criação de um sistema que oferecesse várias opções de abordagem para os conflitos trazidos pelas pessoas, ou seja, "I tried to look at each of the different processes and see whether we could work out some kind of taxonomy of which disputes ought to go where, and which doors are appropriate for which disputes." ${ }^{7738}$

Ademais, consiste em olhar o conflito sobre diferentes perspectivas, apresentando-o como forma de tratamento a mediação, a negociação, a arbitragem, dentre outros mecanismos: "tentou olhar para cada um dos diferentes processos e trabalhou com o tipo de taxonomia de disputas, observando quais as portas eram apropriadas para o tratamento da demanda." ${ }^{39}$ A proposta de Sander caracteriza-se por integrar, em um único local, vários modos de processamento de conflitos.

Dessa forma, ao invés de apenas uma porta (processo judicial), o Tribunal Múltiplas Portas abrange um sistema mais amplo, com vários tipos de procedimentos, aos quais as partes são direcionadas de acordo com a particularidade de seu conflito. ${ }^{40}$ Como manifesta Barbosa, "a característica-chave do Fórum de Múltiplas Portas é a sua fase inicial, no qual cada disputa é analisada de acordo com diversos critérios e encaminhada para o procedimento mais adequado. A partir daí, o caso será tratado conforme o processo indicado." ${ }^{41}$

Inicialmente, realiza-se uma avaliação do conflito, por meio de pessoal especializado, identificando às pessoas o método de tratamento mais adequado ao seu conflito (porta mais indicada). A importância do sistema em estudo reside em que as técnicas convivam de forma harmoniosa e articulada com o sistema de justiça, recebendo o suporte e o financiamento do Poder Público. A pertinência da adoção das Múltiplas Portas em razão de que é preciso reconhecer que partes e conflitos são mais bem assistidos com métodos específicos diante das características do seu litígio. Por essa razão, afirma-se que se objetiva informar às partes acerca das alternativas disponíveis para tratamento do seu conflito, auxiliando-as na escolha do mecanismo mais apropriado para a disputa particular. ${ }^{42}$

A implementação do Múltiplas Portas é disponibilizar mecanismos para tratar os conflitos trazidos ao Poder Judiciário. Ao abordar o conflito, realiza-se uma avaliação, identificando-se as partes ou interessados para, então, apontar o instrumento mais adequado à satisfação dos interesses das pessoas envolvidas no conflito. Ademais, destaca-se que o profissional responsável pela condução do caso pode ser um negociador, um conciliador, um mediador, um árbitro ou um juiz. O importante é identificar o método específico ao problema apresentado. ${ }^{43}$ 
Na etapa seguinte, há o processo de diagnóstico do conflito, o qual pode ser dividido em duas funções principais: entrevista e aconselhamento. Na entrevista, realizam-se perguntas a fim de identificar o problema, encerrando-se a etapa com o resumo da situação e a aceitação da parte; no aconselhamento, analisam-se as soluções potenciais, com suas prováveis consequências, negativas e positivas, identificando, ao final, a porta mais adequada ao tratamento do conflito.

Dessa forma, o Fórum Múltiplas Portas $^{44}$ tem a função de receber o conflito, encaminhando-o, podendo ser visualizado como uma roda. No centro da roda, estão localizadas a fase de entrada e a unidade de referência; nos raios da roda, encontram-se as portas de tratamento do conflito (as opções de referência). Posteriormente à triagem e ao diagnóstico de admissão, o conflito é submetido a um dos processos de tratamento (opções) e, em não sendo bem sucedida a primeira opção, o conflito retorna para o centro da roda, submetendo-se à nova reavaliação e, após, a novo tratamento. ${ }^{45}$

Compreende-se, portanto, que o Fórum Múltiplas Portas caracteriza-se por uma mesa de entradas e um centro de diagnóstico que, a partir do relato do caso feito pelas próprias pessoas envolvidas no conflito, o profissional especializado as orienta para o meio mais adequado de tratamento.

Para determinar a porta a ser indicada, devem ser observados quatro fatores: ${ }^{46}$ a) a natureza da disputa; b) o relacionamento entre as partes; c) o valor do pedido e o valor do processo; d) a velocidade, considerando-se a necessidade de resposta rápida e urgente intervenção. ${ }^{47}$ No tocante à natureza da disputa, ressalta-se que há uma necessidade de desenvolvimento de um mecanismo flexível que possa atender de forma mais adequada a um conflito, pois "I do not believe that a court is the most effective way to perform this kind of sifting task." ${ }^{4849}$

Há problemas policêntricos não adequados para a abordagem adjudicatória, aos quais não cabe uma decisão "tudo ou nada". Da mesma forma, deve ser observado o relacionamento existente entre as partes, eis que aquele que existe há algum tempo tem forças para auxiliar as pessoas envolvidas a alcançarem a resposta ao litígio, bem como possibilita que o conflito seja tratado na sua profundidade e não apenas na superfície. ${ }^{50}$

Um dos aspectos primordiais para responder de forma adequada ao conflito é observar os objetivos das partes e como elas podem ser satisfeitas por meio dos diversos processos/ métodos. Para compreender essa afirmação, Sander e Rozdeiczer ${ }^{51}$ exemplificam: Ana está em meio a um divórcio quando o procura enquanto advogado e solicita o seu aconselhamento de como proceder. A escolha de Ana dependerá de quais objetivos ela pretende alcançar. Ou seja, ela deseja preservar um bom relacionamento com John? Ela deseja que John participe da criação das crianças, ou ela prefere que ele não as veja? O quão importante é para ela maximizar o ganho monetário com o divórcio? O quão importante é a sua preocupação financeira diante do relacionamento com John? Ela deseja manter os assuntos do divórcio em particular? Ela tem o desejo de vingança pública? Antes de saber o que Ana realmente 
deseja, torna-se impossível tomar qualquer decisão relacionada à porta mais indicada ao seu litígio. Com a tabela a seguir, verificam-se objetivos possíveis para a Ana, ou qualquer outra parte, e os graus de satisfação de cada método.

Tabela 1 - Objetivos e Graus de Satisfação nos Métodos Complementares

\begin{tabular}{|c|c|c|c|c|c|c|c|}
\hline \multicolumn{5}{|c|}{$0=$ dificilmente satisfaz o objetivo } & \multicolumn{3}{|c|}{$\begin{array}{l}2=\text { satisfaz o objetivo substancial- } \\
\text { mente }\end{array}$} \\
\hline \multicolumn{5}{|c|}{$1=$ satisfaz parcialmente o objetivo } & \multicolumn{3}{|c|}{$3=$ satisfaz muito o objetivo } \\
\hline & Método/Objetivo & Mediação & Minitrial & $\begin{array}{l}\text { Summary } \\
\text { Jury Trial }\end{array}$ & $\begin{array}{c}\text { Early } \\
\text { Neutral } \\
\text { Evaluation }\end{array}$ & Arbitragem & Adjudicação \\
\hline 1 & Velocidade & 3 & 2 & 2 & 3 & $0-2$ & 0 \\
\hline 2 & Privacidade & 3 & 3 & 1 & 2 & 1 & 0 \\
\hline 3 & Vingança Pública & 0 & 1 & 1 & 1 & 2 & 3 \\
\hline 4 & Opinião Neutra & 1 & 1 & 2 & 2 & 3 & 3 \\
\hline 5 & Minimizar Custos & 3 & 2 & 2 & 3 & $0-2$ & 0 \\
\hline 6 & $\begin{array}{l}\text { Manter/Melhorar Rela- } \\
\text { cionamento }\end{array}$ & 3 & 2 & 2 & 1 & 1 & 0 \\
\hline 7 & Precedente & $0-1$ & $0-1$ & $0-1$ & $0-1$ & 2 & 3 \\
\hline 8 & Max/Min Recuperação & $0(3)$ & 1 & 1 & 1 & 2 & 3 \\
\hline 9 & Criar Novas Soluções & 3 & 3 & 1 & 2 & 1 & 0 \\
\hline 10 & $\begin{array}{l}\text { Controle da Parte do } \\
\text { Processo }\end{array}$ & 3 & 2 & 1 & 1 & $1-2$ & 0 \\
\hline 11 & $\begin{array}{l}\text { Controle de Parte da } \\
\text { Renda }\end{array}$ & 3 & 3 & 1 & 2 & 1 & 0 \\
\hline 12 & $\begin{array}{l}\text { Transferência da res- } \\
\text { ponsabilidade para uma } \\
\text { Terceira Pessoa }\end{array}$ & $0-1$ & 1 & 2 & 2 & 3 & 3 \\
\hline 13 & $\begin{array}{l}\text { Supervisão do Tribunal } \\
\text { ou Compulsão }\end{array}$ & $0-2$ & 0 & 1 & 1 & 2 & 3 \\
\hline 14 & $\begin{array}{l}\text { Transformação das } \\
\text { Partes }\end{array}$ & 3 & 1 & 0 & 0 & 0 & 0 \\
\hline 15 & Processo satisfatório & 3 & 3 & 2 & 2 & 2 & 0 \\
\hline 16 & $\begin{array}{l}\text { Melhorar a Compreen- } \\
\text { são da Disputa }\end{array}$ & 3 & 3 & 1 & 2 & 2 & 1 \\
\hline
\end{tabular}

Fonte: Sander e Rozdeiczer (2006, p. 6).

No exemplo anteriormente citado, deve Ana responder a primeira pergunta sobre o tipo de relacionamento que deseja com o John com o término do divórcio. Se o casal tiver filhos, deve, ainda, considerar o relacionamento que seja bom para os filhos também. No quadro, observa-se que a mediação apresenta as melhores chances de preservar e, possivelmente, melhorar a relação preexistente. $O$ procedimento mediativo é o único a receber pontuação máxima nas dimensões custo, velocidade e manutenção do relacionamento anterior. Por outro lado, o processo judicial frequentemente ameaça destruir esse relacionamento. Portanto, as características específicas do caso e os objetivos das pessoas envolvidas permitem alcançar uma resposta eficaz e satisfatória, revelando-se a porta mais adequada. ${ }^{52}$ 
Nesse sentido, Sander apresentou como portas de tratamento a mediação, a conciliação, a arbitragem, os processos híbridos, como a mediação e a arbitragem (med-arb ou arb-med), o mini-trial, o summary jury trial, o case evaluation, o ombudsman e a adjudicação. ${ }^{53}$

A primeira porta, denominada de mediação, consoante manifesta Spengler, ${ }^{54}$ constitui-se como um processo em que o terceiro auxilia os participantes, em uma situação conflitiva, a tratá-la, permitindo que a solução seja aceitável para os envolvidos, de forma que satisfaça seus anseios e desejos. ${ }^{55}$ Por esse método, os conflitantes devem ser encorajados a ouvir e a entender os pensamentos e sentimentos uns dos outros, possibilitando que juntos alcancem uma resposta favorável a ambos.

Dessa forma, a meta da mediação é responsabilizar os conflitantes pelo tratamento do litígio que os une a partir de uma ética da alteridade, encontrando, a partir do auxílio de um mediador, uma garantia de sucesso, "aparando as arestas" e as dificuldades das partes, bem como compreendendo as emoções reprimidas e buscando um consenso que atinja o interesse das partes e a paz social..$^{56}$

A mediação ocorre pela intervenção de um terceiro, de uma terceira pessoa que se interpõe entre os dois protagonistas de um conflito, isto é, de duas pessoas, comunidades ou povos que se confrontam e estão um contra o outro. Assim, a mediação busca passar os dois protagonistas da adversidade à conversação, levando-os a virar-se um para o outro para se falarem, compreenderem e, se possível, construir juntos um compromisso que abra caminho à reconciliação. 5859

Denominada de conciliação, a segunda porta é entendida como a atividade desenvolvida para incentivar, facilitar e auxiliar as partes à autocomposição, adotando, porém, uma metodologia que permita a apresentação de proposição por parte do conciliador. Nesse rumo, "tem como método a participação mais efetiva desse terceiro na proposta de solução, tendo por escopo a solução do conflito que lhe é concretamente apresentado nas petições das partes."60

Compreende-se que a conciliação oportuniza às partes o debate e a posterior exploração das possibilidades de resolução aceitáveis a todos. Por essa razão, bem como pela tradição histórica diante dos demais métodos, esse procedimento tende a ser o mais utilizado pelo Fórum de Múltiplas Portas. Aponta-se como uma das principais vantagens a pacificação social, pois, diverso do que se verifica na sentença judicial, "o acordo da conciliação não é imposto autoritariamente e logra ventilar emoções das partes para acalmá-las, podendo atingir a lide sociológica, em geral, mais ampla do que aquela que emergiu "como simples ponta do iceberg."”61

Adiciona-se à função de pacificação social a racionalização da aplicação da Justiça com a consequente redução do congestionamento dos juízos, educação da população na negociação de suas próprias disputas, aumento da legitimidade do Poder Judiciário e intensificação da participação democrática popular nos casos em que o conciliador é escolhido entre a comunidade. ${ }^{62}$ 
A seu turno, a terceira porta, arbitragem, consiste na escolha pelas partes de um terceiro, denominado de árbitro, independente e imparcial, o qual é responsável por proferir a decisão equivalente à sentença judicial. ${ }^{63}$ Assim, conceitua-se arbitragem como o meio pelo qual o estado, em vez de interferir diretamente nos conflitos de interesses, impondo a sua decisão, permite que uma terceira pessoa o faça, a partir de um procedimento e da observação de regras mínimas, mediante uma decisão com autoridade idêntica à de uma sentença judicial.

Dessa forma, as partes, ao optarem pela arbitragem, afastam a jurisdição estatal e substituem por outra estratégia de tratamento de conflitos, reconhecida e regulada pelo estado, permitindo a execução das decisões proferidas, bem como que sejam anuladas aquelas que não tenham observado um mínimo de regras exigidas pelo legislador. ${ }^{64} \mathrm{O}$ terceiro, denominado de árbitro, tem total confiança das partes, recebendo autoridade suficiente para impor uma solução satisfatória. Nesse sentido, consoante manifestam Goldberg, Sander, Rogers e Cole, ${ }^{65}$ a arbitragem apresenta as seguintes vantagens: a) terceiro/árbitro com conhecimento especializado; b) reconhecimento/legitimidade da decisão; c) privacidade do procedimento; d) informalidade do procedimento; e) baixo custo; e f) rapidez.

Por sua vez, a avaliação preliminar neutra (Early Neutral Evaluation), quarta porta aqui apresentada, caracteriza-se por fornecer às partes um parecer fundamentado por um advogado, juiz ou promotor de justiça. Trata-se, portanto, de uma avaliação prévia mediante uma opinião fundamentada de forma oral, ${ }^{66}$ que permite às partes retornarem à negociação com uma opinião especializada.

$\mathrm{Na}$ audiência com o avaliador, o qual explica as vantagens e a segurança do procedimento, as partes apresentam de forma sumária sua argumentação jurídica, descrevendo os fatos relevantes e indicando as provas que pretendem produzir para, então, possibilitar ao avaliador a confecção de um parecer fundamentando, não vinculante para as partes. ${ }^{67}$ Se a controvérsia não é solucionada, a avaliação permanece em confidencialidade, podendo o avaliador auxiliar as partes a encontrar o procedimento mais simples e mais rápido no tribunal. ${ }^{68}$

O Summary Jury Trial configura-se em um procedimento sumário diante de um júri, para verificação da tese e da reação dos jurados, os quais, geralmente, não possuem conhecimento do seu papel consultivo, ou seja, aos jurados não se menciona o seu papel de aconselhamento até a entrega do veredicto, razão pela qual são recomendados a tratar o conflito com a seriedade que um júri real requer. ${ }^{69}$

Assim, "o procedimento é sumário e conta com um resumo das teses e provas, sendo o júri chamado para emitir um parecer opinativo. Normalmente, é um mecanismo utilizado para casos complexos que demandem tempo e alto custo." 70 71, ou, ainda, "for those novel or unusual cases in which the jury's verdict is difficult to predict and that difficulty is deterring settlement."72 73 
Há, ainda, o Mini-Trial, o qual consiste em apresentações sumárias realizadas pelos advogados de cada parte a um painel, composto por um conselheiro neutro e por executivos, buscando negociar a resolução da disputa. Se as partes diretamente envolvidas forem incapazes de fazê-lo, podem solicitar ao conselheiro neutro uma previsão de resultado possível do litígio. ${ }^{74}$ Por sua vez, a Court-annexed arbitration utiliza arbitragem anexa ao juízo tradicional, ou seja, as partes são incentivadas e encorajadas a participar da arbitragem como mecanismo de tratamento do conflito, a qual é inserida pelo Poder Judiciário em seu programa, mantendo acordos e convênios com instituições privadas de arbitragem para atuação conjunta. ${ }^{75}$

No Med-Arb e Arb-Med, as partes anuem em realizar a mediação ou a arbitragem e, inexitosa, passa-se ao outro procedimento. ${ }^{76}$ Trata-se de procedimentos privados e espontâneos, os quais podem ser realizados sob orientação coordenada. Destaca-se que, no processo Med-Arb , a função neutra se dá primeiro como mediador. Se falhar a mediação, a mesma pessoa neutral servirá como árbitro, porém, nesse caso, emitindo decisão. Compreende-se que o "sistema med/arb proporciona total segurança a quem entra na mediação, pois, de um modo ou de outro, sairá com seu conflito resolvido, chegando a um acordo ou, imediatamente, obtendo o laudo."77

A seu turno na Arb-Med ${ }^{78}$ ocorre o contrário. Isto é, realiza-se o procedimento de arbitragem, alcançando-se a sentença, sem anunciá-la às partes, iniciando-se, antes, os procedimentos de mediação. ${ }^{79}$ Assim, não ocorrendo o acordo, revela-se a sentença antes prolatada.

A porta denominada de Ombudsman ${ }^{80}$ (Ouvidor) caracteriza-se por ser uma pessoa nomeada por uma instituição para tutelar seus direitos contra a falta, a disfunção, os abusos ou os retardos dessa mesma instituição. Destaca-se que ela não possui o poder de impor uma decisão, nem de anular, revogar, modificar os atos da instituição, mas que atua formulando observações e recomendações, buscando a satisfação das reclamações dos interessados. ${ }^{81}$

Estudos mais recentes apontam duas inovações no sistema Múltiplas Portas, salientando-se que o fórum não se limita a um número determinado de portas, podendo surgir novas diante da evolução dos conflitos e da própria sociedade. ${ }^{82}$ Nessa ótica, aponta-se a porta denominada de Collaborative Law (Direito Colaborador), cuja aplicabilidade se dá no Direito de Família, quando o casal, durante o processo de divórcio, concorda em realizar um acordo sem recorrer ao Poder Judiciário. A diferença dessa porta das demais negociações com advogados, por exemplo, reside no fato de que, inicialmente, as partes (casal) assinem um acordo de participação.

Após, devem trocar informações financeiras completas, de forma que cada parte possa ter total acesso às informações e, portanto, tomar decisões sem alcançar um litígio judicial. Outra nova porta, chamada de Parenting Coordination (Coordenação Familiar), é um mecanismo utilizado em conflitos na guarda de filhos diante de pais divorciados. Dessa forma, o método busca auxiliar os pais no cumprimento da decisão judicial, bem como educar os pais na observação do impacto do conflito no seu filho. ${ }^{83}$ 
A porta mais tradicional, adjudicação, configura-se no litígio da parte que procura o Poder Judiciário, propondo a ação judicial, o qual é decidido pelo terceiro, aqui denominado de juiz, cuja decisão possui efeito coercitivo e atinge a todos os fatos do processo. Conforme manifestam Morais e Spengler, ${ }^{84}$ o caráter contencioso caracteriza o modelo da porta em estudo. Ademais, "[...] tratar o conflito judicialmente é atribuir ao magistrado o poder de dizer quem ganha e quem perde no litígio." ${ }^{55}$

Cada método tem a capacidade de ativar algumas funcionalidades que facilitam o alcance do objetivo das partes. Por exemplo, a mediação e o minitrial permitem a comunicação e maximizam as chances das pessoas envolvidas no conflito de obter uma resposta a partir de valores comuns. O Summary Jury Trial e a Avaliação Preliminar Neutra proporcionam uma oportunidade para verificar os pontos fortes e fracos do caso, possibilitando a tomada de decisão mais informada e uma solução possível. Por sua vez, a adjudicação e a arbitragem fornecem alguns instrumentos processuais que podem atender às necessidades das partes, incluindo a execução das decisões.

Nesse contexto, o quadro a seguir apresenta as características das principais portas, o que permite conhecer os benefícios que cada uma traz ao conflito.

Tabela 2 - Características dos Métodos Complementares

\begin{tabular}{l|l|c|c|c|c|c|c}
\hline & & \multicolumn{2}{|c|}{$\begin{array}{c}\text { Resolução do } \\
\text { Problema }\end{array}$} & \multicolumn{2}{c|}{$\begin{array}{c}\text { Conferência da } \\
\text { Realidade }\end{array}$} & \multicolumn{2}{c}{ Adjudicação } \\
\hline 1 & Cediação & Minitrial & $\begin{array}{c}\text { Summary } \\
\text { Jury Trial }\end{array}$ & $\begin{array}{c}\text { Avaliação } \\
\text { Prelim. } \\
\text { Neutra }\end{array}$ & Arbitragem & Adjudicação \\
\hline 2 & $\begin{array}{l}\text { Bom relacionamento } \\
\text { entre os Advogados }\end{array}$ & 3 & 2 & 1 & 1 & 0 & 0 \\
\hline 3 & $\begin{array}{l}\text { Bom } \\
\text { entacionamento as Partes }\end{array}$ & 3 & 2 & 1 & 1 & 0 & 0 \\
\hline 4 & $\begin{array}{l}\text { Partes dispostas a } \\
\text { Resolver o Conflito }\end{array}$ & 3 & 2 & 1 & 1 & 0 & 0 \\
\hline 5 & $\begin{array}{l}\text { Uma ou ambas as } \\
\text { partes deseja(m) se } \\
\text { desculpar }\end{array}$ & 3 & 3 & 1 & 1 & 0 & 0 \\
\hline 6 & $\begin{array}{l}\text { Desejo de Acordo } \\
\text { Pessoas externas } \\
\text { envolvidas }\end{array}$ & 3 & 2 & 2 & 2 & 1 & 1 \\
\hline 7 & $\begin{array}{l}\text { Muitos assuntos } \\
\text { envolvidos no Caso }\end{array}$ & 3 & 3 & 1 & 1 & 1 & 0 \\
\hline 8 & $\begin{array}{l}\text { Parte se beneficia } \\
\text { com o processo } \\
\text { judicial }\end{array}$ & $0-2$ & 1 & 2 & 1 & 2 & 3 \\
\hline 9 & $\begin{array}{l}\text { Especialista ou } \\
\text { Neutro requerido }\end{array}$ & 3 & 3 & 1 & 3 & 3 & 1 \\
\hline
\end{tabular}

Fonte: Sander e Rozdeiczer (2006, p. 6). 
Destaca-se que, justamente em razão da crítica existente com a porta da jurisdição tradicional, novos métodos surgiram, com a meta de atender às especificidades de cada conflito. No entanto, não se está aqui excluindo da apreciação do Poder Judiciário toda e qualquer questão, apenas se objetiva adequar o tratamento ao tipo de conflito, razão pela qual o Distrito de Columbia, nos Estados Unidos da América, encontrou, no sistema das Múltiplas Portas, uma resposta aos obstáculos do seu sistema de Justiça, o que será abordado no tópico seguinte.

Assim, conhecido como "Palácio de Justiça Múltiplas Portas" ou "Fórum Múltiplas Portas", os tribunais foram estabelecidos, de forma experimental e inicial, ${ }^{86} \mathrm{em}$ Tulsa, Okalahoma, Houston, Texas, e no Tribunal Superior do Distrito de Columbia. Outros projetos (projetos-piloto) foram iniciados em Nova Jersey e Cambridge. ${ }^{87}$ A partir dessas experiências, a ideia espalhou-se para outros Tribunais no mundo, por exemplo, Austrália, Inglaterra e Nigéria, apresentando resultados positivos na concretização de uma cultura de paz e no atendimento às necessidades das pessoas de forma satisfatória e adequada.

\section{CONSIDERAÇÕES FINAIS}

O modelo brasileiro, inspirado na política norte-americana, assemelha-se por apresentar duas portas - mediação e conciliação - determinando aos tribunais estaduais a implementação de núcleos para resolução dos conflitos judicializados. Nesse contexto, compreende-se que o estabelecimento de uma política pública judiciária a qual permita organicidade, qualidade e controle à sua prática se justifica para garantir que os meios complementares de tratamento de conflitos, em especial, os meios consensuais - mediação e conciliação - tenham um uso correto e se constituam em um modo efetivo de assegurar o verdadeiro e adequado acesso a uma ordem jurídica justa.

No entanto, a política judiciária brasileira de tratamento de conflitos - a partir da Resolução no ${ }^{\circ} .125$ de 2010 do Conselho Nacional de Justiça - apresenta fragilidades ao não instituir um sistema de triagem de conflitos, como observado no multiportas. A triagem permite que seja realizada a taxinomia do conflito e, portanto, o método mais adequado é utilizado, permitindo o tratamento eficaz e qualificado do conflito. Reconhece-se o avanço do Poder Judiciário no Brasil ao implantar as formas complementares de tratamento de conflito, porém, ao institucionalizá-las, transforma-as em mera fase do processo, com um rito a ser seguido, sem a capacitação adequada dos facilitadores e da observação do método de acordo com as características do conflito e da relação das pessoas envolvidas.

A experiência norte-americana, a partir do Tribunal Múltiplas Portas, apresenta um modelo de política pública que qualifica a resposta ao conflito ao atender de modo mais acertado às relações sociais e ao tipo do conflito a ele direcionado, o que se visualizou nas portas especializadas com direcionamento de casos (litígios) para o seu tratamento, considerando-se, nessa ótica, as características e peculiaridades de cada conflito e de seus envolvidos. 
Desse modo, o Tribunal Múltiplas Portas, a partir da sua organização, estrutura e da atuação do terceiro, permite propor contribuições à política pública brasileira por reconhecer, nas características do conflito, um método adequado para o seu tratamento, garantindo a satisfação daqueles que se encontram na situação conflitiva, o que contribui para o incentivo aos mecanismos autocompositivos, para a compreensão dos problemas nacionais relacionados à solução de conflitos, aprimorando a prática dos métodos consensuais e desenvolvendo uma nova cultura de paz social.

Tais contribuições revelam-se no encaminhamento do conflito adequado à mediação; no reconhecimento dos interesses envolvidos no conflito e na identificação da relação entre as partes, o que possibilitará ao terceiro mediador uma atuação adequada, aprimorada e o uso qualificado das técnicas e habilidades adquiridas, contribuindo, dessa forma, para o seu reconhecimento e para a credibilidade da sua função essencial ao tratamento do conflito.

$\mathrm{O}$ adequado tratamento do conflito garante o acesso a uma ordem jurídica justa e fortalece a participação social do cidadão, fomentando uma cultura de paz, de alteridade e de tratamento de conflitos de forma qualitativa, considerando cada pessoa envolvida, o tipo de conflito, as necessidades e os interesses a serem atendidos.

\section{REFERÊNCIAS}

BARBOSA, Ivan Machado. Fórum de múltiplas portas: uma proposta de aprimoramento processual. In: AZEVEDO, André Gomma de. Estudos em arbitragem, mediação e negociação. Brasília: Ed. Grupos de Pesquisa, 2003. v. 2. Disponível em: < http://vsites.unb. br/ fd/gt/Volume2.pdf >. Acesso em: 23 jun. 2013.

BRADY, Robert A. The Constitution of the United States of America. 2007. Disponível em: <https://www.gpo.gov/fdsys/pkg/CDOC-110hdoc50/pdf/CDOC-110hdoc50.pdf>. Acesso em: 11 jan. 2016.

CALMON, Petrônio. Fundamentos da mediação e da conciliação. Brasília: Gazeta Jurídica, 2015.

CRESPO, Mariana Hernandez. Diálogo entre os professores Frank Sander e Mariana Hernandez Crespo. In: ALMEIDA, Rafael Alves de; ALMEIDA, Tania; CRESPO, Mariana Hernandez. Tribunal multiportas: investindo no capital social para maximizar o sistema de solução de conflitos no Brasil. Rio de Janeiro: FGV, 2012. p. 25-38.

CRESPO, Mariana Hernandez; SANDER, Frank. Evolution of the multi- door courthouse. University of St. Thomas Law Journal, Saint Paul, MN, v. 5, n. 3, p. 670, 2008. Disponível em: <http://papers.ssrn. com/sol3/papers.cfm?abstract_id=1265221>. Acesso em: 28 maio 2014. 
FRENCH, Robert. Perspectives on court annexed alternative dispute resolution. 2009. Disponível em: <http:/www.hcourt.gov.au/assets/publications/speeches/current-justices/ frenchcj/frenchcj27july09.pdf>. Acesso em: 28 maio 2014.

GABBAY, Daniela Monteiro. Mediação \& Judiciário no Brasil e nos EUA: condições, desafios e limites para a institucionalização da mediação no judiciário. Brasília: Gazeta Jurídica, 2013.

GOLDBERG, Stephen B. et al. Dispute resolution: negotiation, mediation, and other processes. 5. ed. New York: Aspen Publishers, 2012.

KEPPEN, Luiz Fernando Tomasi; MARTINS, Nadia Bevilaqua. Introdução à resolução alternativa de conflitos: negociação, mediação, levantamento de fatos, avaliação técnica independente. Curitiba: JM Livraria Jurídica, 2009.

LUCHIARI, Valeria Ferioli Lagrasta. Mediação judicial: análise da realidade brasileira: origem e evolução até a Resolução n ${ }^{\text {o. }}$ 125, do Conselho Nacional de Justiça. Rio de Janeiro: Forense, 2012.

MENKEL-MEADOW, Carrie. Regulation of dispute resolution in the United States of America: from the formal to the informal to the 'semi-formal'. In: STEFFEK, Felix et al. Regulating dispute resolution: $\mathrm{adr}$ and access to justice at the crossroads. 2013. Disponível em: $<$ http://scholarship.law.georgetown.edu/cgi/viewcontent.cgi article $=2300 \&$ context $=$ fac pub>. Acesso em: 18 jan. 2016.

MOORE, Christoper W. O processo de mediação: estratégias práticas para a resolução de conflitos. Tradução de Magda França Lopes. Porto Alegre: Artmed, 1998.

MORAIS, Jose Luis Bolzan de; SPENGLER, Fabiana Marion. Mediação e arbitragem: alternativas à jurisdição! Porto Alegre: Livraria do Advogado, 2012.

MULLER, Jean - Marie. Não violência na educação. Tradução de Tônia Van Acker. São Paulo: Palas Athenas, 2006.

NUNES, Andrine Oliveira; SALES, Lilia Maia de Moraes. A possibilidade do alcance da justiça por meio de mecanismos alternativos associados ao judiciário. 2010. Disponível em: <http://www.conpedi.org.br/manaus/arquivos/anais/florianopolis/Inte gra.pdf>. Acesso em: 23 jun. 2013.

OLIVEIRA, Luthyana Demarchi de; SPENGLER, Fabiana Marion. O fórum múltiplas portas como política pública de acesso à justiça e à pacificação social. Curitiba: Multideia, 2013.

SALES, Lilia Maia de Morais; SOUSA, Mariana Almeida de. O sistema de múltiplas portas e o judiciário brasileiro. Direitos Fundamentais \& Justiça, v. 5, n. 16, p. 204-220, jul./set. 2011. 
SANDER, Frank. Varieties of dispute processing. In: POUND conference: perspectives on justice in the future. Minnesota: West Publishing Co., 1979. p. 65-87.

SANDER, Frank; ROZDEICZER, Lukasz. Matching cases and dispute resolution procedures: detailed analysis leading to a mediation-centered approach. Harvard Negotiation Law Review, v. 11, p. 1-28, 2006.nd possibilities. Penn State Law Review, United States, v. 108, n. 1, p. 327-348, 2003.

SIFUENTES, Mônica. Tribunal multiportas. Jus Navigandi, Teresina, v. 11, n. 972, fev. 2006. Disponível em: < http://jus.com.br/artigos/8047/tribunal-multiportas>. Acesso em: 28 maio 2014.

SOARES, Guido Fernando Silva. Common law. introdução ao direito dos EUA. 2. ed. São Paulo: Revista dos Tribunais, 2000.

SOURDIN, Tania. Alternative dispute resolution and the courts. Leichhardt: The Federation Press, 2004.

SPENGLER, Fabiana Marion. Da jurisdição à mediação: por uma outra cultura no Tratamento de Conflitos. Ijuí: Unijuí, 2010.

. Fundamentos políticas da mediação comunitária. Ijuí: editora Unijuí, 2012.

UNIFORM LAW COMMISSION. The national conference of commissioners on United

States Laws. Disponível em: < http:/www.uniformlaws.org/Act.aspx?title=Mediation\%20

Act $>$. Acesso em: 18 jan. 2016.

VIEIRA, Andréia Costa. Civil law e common law: Os dois grandes sistemas legais comparados. Porto Alegre: Sergio Antonio Fabris Editor, 2007.

1 SOURDIN, Tania. Alternative dispute resolution and the courts. Leichhardt: the Federation Press, 2004.

2 SENFT, Louise Phipps; SAVAGE, Cynthia A. ADR in the courts: progress, problems and possibilities. Penn

State Law Review, United States, v. 108, n. 1, p. 327-348, 2003.

3 O presente termo pode ser compreendido como "Centro Abrangente de Justiça".

4 CRESPO, Mariana Hernandez. Diálogo entre os professores Frank Sander e Mariana Hernandez Crespo. In: ALMEIDA, Rafael Alves de; ALMEIDA, Tania; CRESPO, Mariana Hernandez. Tribunal multiportas: investindo no capital social para maximizar o sistema de solução de conflitos no Brasil. Rio de Janeiro: FGV, 2012. p. 25-38.

5 Tradução livre: "quais são as características significantes dos diversos mecanismos de resolução de conflitos (tais como, adjudicação, arbitragem, mediação, negociação, e várias misturas desses e outros métodos)?"

6 Tradução livre: "como essas características podem ser usadas, considerando-se a variedade dos conflitos que se apresentam, para desenvolver critérios racionais para direcionar diversos tipos de conflitos a métodos diversos de tratamento de conflitos?"

7 SANDER, Frank. Varieties of dispute processing. In: POUND conference: perspectives on justice in the future. Minnesota: West Publishing Co., 1979. p. 65-69.

8 Para Sander e Rozdeiczer (In: SANDER, Frank; ROZDEICZER, Lukasz. Matching cases and dispute resolution procedures: detailed analysis leading to a mediation-centered approach. Harvard Negotiation Law Review, v. 11, p. 1, 2006), "one of the most challenging problems in the field of alternative methods of dispute resolution $(\mathrm{ADR})$ is deciding which process or processes (e.g., arbitration, mediation, trial, or some hybrid of these 
primary processes) are most appropriate for a particular dispute". Tradução livre: "um dos problemas mais desafiadores no âmbito dos métodos de resolução alternativa de conflitos (ADR) é decidir qual processo ou processos é mais apropriado para determinado conflito".

9 SANDER, Frank; ROZDEICZER, Lukasz. Matching cases and dispute resolution procedures: detailed analysis leading to a mediation-centered approach. Harvard Negotiation Law Review, v. 11, p. 1-28, 2006.

10 Destaca-se que o presente artigo não objetiva realizar a abordagem da política pública brasileira de tratamento de conflitos, mas apresentar contribuições a ela a partir da vasta literatura publicada que revela suas fragilidades.

11 A referida Resolução tem por escopo instituir a Política Judiciária Nacional de tratamento de conflito de interesses, assegurando a todas as pessoas o adequado método para resposta ao seu conflito de acordo com a natureza e a peculiaridade. Para isso, compete aos órgãos judiciários, no prazo de 12 meses, oferecer a mediação e a conciliação como métodos de resolução de conflitos, prestando atendimento e orientação à população.

12 No sistema do Common Law (sistema jurídico anglo-saxão), adotado por países como Estados Unidos da América (com exceção do Estado de Louisiana, Reino Unido, Austrália, o Direito é declarado pelo juiz (judge made law), sendo o precedente judicial (case law) a principal fonte jurídica. Dessa forma, a partir do confronto entre um precedente e um novo caso, aplica-se a técnica das distinções, a qual consiste na possibilidade de ajustar, completar ou mesmo reformular a regra, para dar a melhor e mais razoável solução ao litígio. Os princípios de direito são inteiramente construídos pelas cortes de justiça, sem que haja qualquer lei escrita a respeito (VIEIRA, Andréia Costa. Civil law e common law: os dois grandes sistemas legais comparados. Porto Alegre: Sergio Antonio Fabris Editor, 2007).

13 Para maiores informações, pode ser acessado o sítio eletrônico da US Supreme Court. Disponível em: <http:// www.supremecourt.gov $>$.

14 US Statutes se refere à legislação ordinária federal norte-americana.

15 Section I: "The judicial Power of the United States, shall be vested in one supreme Court, and in such inferior Courts as the Congress may from time to time ordain and establish. The Judges, both of the supreme and inferior Courts, shall hold their Offices during good Behaviour, and shall, at stated Times, receive for their Services, a Compensation, which shall not be diminished during their Continuance in Office". Tradução livre: "Seção I: "O poder judicial dos Estados Unidos da América será investido em uma Corte Suprema, e em Tribunais inferiores que o Congresso pode, de tempos em tempos, ordenar e estabelecer. Os juízes tanto da Corte Suprema como dos Tribunais inferiores conservarão seus cargos mediante boa conduta, devendo, em prazos determinados, receber por seus serviços por meio de uma remuneração que não poderá ser reduzida durante a sua permanência no cargo".

16 Section II: "1: The judicial Power shall extend to all Cases, in Law and Equity, arising under this Constitution, the Laws of the United States, and Treaties made, or which shall be made, under their Authority;-to all Cases affecting Ambassadors, other public Ministers and Consuls; - to all Cases of admiralty and maritime Jurisdiction; - to Controversies to which the United States shall be a Party;- - to Controversies between two or more States; - between a State and Citizens of another State - between Citizens of different States, - between Citizens of the same State claiming Lands under Grants of different States, and between a State, or the Citizens thereof, and foreign States, Citizens or Subjects.

2: In all Cases affecting Ambassadors, other public Ministers and Consuls, and those in which a State shall be Party, the supreme Court shall have original Jurisdiction. In all the other Cases before mentioned, the supreme Court shall have appellate Jurisdiction, both as to Law and Fact, with such Exceptions, and under such Regulations as the Congress shall make.

3: The Trial of all Crimes, except in Cases of Impeachment, shall be by Jury; and such Trial shall be held in the State where the said Crimes shall have been committed; but when not committed within any State, the Trial shall be at such Place or Places as the Congress may by Law have directed". Tradução livre: "Secção II: "1: O poder judicial deve estender-se a todos os casos, pela Lei e Equidade, decorrente desta Constituição, das leis dos Estados Unidos da América e dos tratados feitos, ou que serão feitos, sob a sua autoridade; -para todos os casos afetando embaixadores, outros ministros e cônsules; -para todos os casos de Jurisdição do almirantado e marítima; -para controvérsias a que os Estados-Membros devem ser Parte; -para controvérsias entre dois ou mais Estados; -entre um Estado e cidadãos de outro Estado ; -entre cidadãos de Estados diferentes, -entre cidadãos do mesmo Estado reivindicando terras de Estados diferentes, e entre um Estado, ou os cidadãos dos mesmos, e Estados estrangeiros, cidadãos ou súditos. 
2: em todos os casos que afetam embaixadores, outros ministros e cônsules e aqueles em que um Estado deve ser parte, a Corte Suprema terá jurisdição original. Em todos os outros casos anteriormente mencionados, a Corte Suprema terá competência de recurso tanto quanto ao direito quanto aos fatos, com as exceções, e sob regulamentos que o Congresso deve fazer.

3: O Julgamento de todos os crimes, exceto em casos de impeachment, será feito por júri; e tal julgamento deve ser realizado no Estado onde os referidos crimes foram cometidos; mas, quando não houver ocorrido em nenhum Estado, o julgamento será em lugar que o Congresso determinará por lei."

17 SOARES, Guido Fernando Silva. Common law. introdução ao direito dos EUA. 2. ed. São Paulo: Revista dos Tribunais, 2000.

18 O District of Columbia pode ser visitado pelo sítio eletrônico <http://www.dcd.uscourts.gov>.

19 SOARES, Guido Fernando Silva. Common law. introdução ao direito dos EUA. 2. ed. São Paulo: Revista dos Tribunais, 2000.

20 Luchiari (In: LUCHIARI, Valeria Ferioli Lagrasta. Mediação judicial: análise da realidade brasileira: origem e evolução até a Resolução no. 125, do Conselho Nacional de Justiça. Rio de Janeiro: Forense, 2012. p. 103) sustenta que "[...] foi nas décadas de 1970 e 1980 que surgiu efetivamente a onda dos mecanismos alternativos de resolução de disputas, que ficou conhecida como "ADR Movement", enquadrando-se perfeitamente no que Mauro Cappelletti denominou de uma das ondas renovadoras do processo [...]".

21 Como refere Luchiari (In: LUCHIARI, Valeria Ferioli Lagrasta. Mediação Judicial: snálise da realidade brasileira: origem e evolução até a Resolução n ${ }^{\text {o. }}$ 125, do Conselho Nacional de Justiça. Rio de Janeiro: Forense, 2012. p. 104), "em 1990, foi editado o Civil Justice Reform Act, pelo Congresso dos Estados Unidos, que lançou determinação aos tribunais distritais federais, no sentido de que desenvolvessem um plano objetivo para reduzir o tempo e as despesas dos processos no prazo de três anos e, ao definir as diretrizes a serem seguidas por esses planos, incluiu a adoção da mediação, do minitrial e do summary jury trial". Nesse sentido, "[...] demandava que as Cortes Federais (District Courts) desenvolvessem planos para redução de custos e demora dos processos judiciais, com ênfase no gerenciamento da demanda, monitoramento da fase instrutória, dentre outras medidas que assegurassem uma resolução mais expedita e menos custosa do processo" (GABBAY, Daniela Monteiro. Mediação \& Judiciário no Brasil e nos EUA: condições, desafios e limites para a institucionalização da mediação no judiciário. Brasília: Gazeta Jurídica, 2013. p. 131).

22 GOLDBERG, Stephen B. et al. Dispute Resolution: negotiation, mediation, and other processes. 5. ed. New York: Aspen Publishers, 2012.

23 O documento "[...] reconheceu a importância dos meios alternativos de solução de conflitos como parte da política nacional de administração judicial, além de requerer que cada District Court desenvolvesse e implementasse o seu próprio programa de meios alternativos de solução de conflitos" (GABBAY, Daniela Monteiro. Mediação \& Judiciário no Brasil e nos EUA: condições, desafios e limites para a institucionalização da mediação no judiciário. Brasília: Gazeta Jurídica, 2013. p. 131-132).

24 LUCHIARI, Valeria Ferioli Lagrasta. Mediação Judicial: análise da realidade brasileira: origem e evolução até a Resolução no. 125, do Conselho Nacional de Justiça. Rio de Janeiro: Forense, 2012.

25 UNIFORM LAW COMMISSION. The national conference of commissioners on United States laws. Disponível em: < http://www.uniformlaws.org/Act.aspx?title=Mediation\%20Act >. Acesso em: 18 jan. 2016.

26 Tradução livre: "a resolução de conflitos nos EUA é formal, informal e semiformal".

27 MENKEL-MEADOW, Carrie. Regulation of dispute resolution in the United States of America: from the formal to the informal to the 'semi-formal'. In: STEFFEK, Felix et al. Regulating dispute resolution: adr and access to justice at the crossroads. 2013. p. 420. Disponível em: <http://scholarship.law.georgetown.edu/cgi/ viewcontent.cgi? article $=2300 \&$ context $=$ facpub $>$. Acesso em: 18 jan. 2016.

28 Tradução livre: "a questão aqui é se processos 'semiformais' podem legitimamente operar em um espaço entre a transparência e a coerência presumida de justiça formal, assim como a confidencialidade, flexibilidade e autodeterminação dos processos informais".

29 MENKEL-MEADOW, Carrie. Regulation of dispute resolution in the United States of America: from the Formal to the Informal to the 'Semi-formal'. In: STEFFEK, Felix et al. Regulating dispute resolution: adr and access to justice at the crossroads. 2013. p. 428. Disponível em: <http://scholarship.law.georgetown.edu/ cgi $/$ viewcontent.cgi?article $=2300 \&$ context $=$ facpub $>$. Acesso em: 18 jan. 2016. 
30 MENKEL-MEADOW, Carrie. Regulation of dispute resolution in the United States of America: from the Formal to the Informal to the 'Semi-formal'. In: STEFFEK, Felix et al. Regulating dispute resolution: adr and access to justice at the crossroads. 2013. p. 236. Disponível em: <http://scholarship.law.georgetown.edu/ cgi/viewcontent.cgi? article $=2300 \&$ context $=$ facpub $>$. Acesso em: 18 jan. 2016.

31 O presente termo pode ser compreendido como "Centro Abrangente de Justiça".

32 O professor Frank Sander explica a tarefa que se constituiu para implementar as propostas da Roscoe Pound Conference: "Well, I think one specific thing that happened is that in the fall of 1976 Jimmy Carter was elected U.S. president. He appointed Griffin Bell as Attorney General of the United States. [Bell] had commented on my paper at the [1976] Pound Conference, and he was very intrigued by what he learned there. So, he set up a special division in the Department of Justice called the Office for Improvements in the Administration of Justice. The, the Pound Conference leaders created a follow-up taskforce to look at what ideas were thrown out there [at the conference], and how they could be advanced and implemented, and Griffin Bell was the head of that. But, there were many other influences. The American Bar Association embraced this idea and set up a special committee initially called the Special Committee on the Resolution of Minor Dispute Resolution. Then in 1993 it became the ABA's Section of Dispute Resolution, which now has 17,000 members. So, the ABA has embraced this. They give a national conference every spring that is very popular in the field. They have put out a journal called Dispute Resolution Magazine, so there have been lots of things that have happened. There also has been state and federal legislation on the subject. One interesting law that exists in a number of states is that lawyers have an ethical duty to apprise clients of different forms of dispute resolution for their cases. So when you come to a lawyer in those states - like Massachusetts, Colorado and New Jersey, and a number of other states - you have to canvas with a client, just the way a doctor ought to do if you come in with some ailment. You say, "My stomach hurts," and the doctor does not say, "Well, let me get out my scalpel and operate". [Doctors] have to tell you your options: "You can take drugs, you can do nothing about it, you can have an operation". So, lawyers ought to be doing the same thing with disputes, and that naturally leads to greater exploration of dispute options. And of course, then the lawyers have to be educated. That is one consequence of that kind of obligation" (GABBAY, 2013, p. 127). Tradução livre: "Bem, acredito que uma coisa específica que aconteceu é que, no outono de 1976, Jimmy Carter foi eleito presidente dos EUA. Ele nomeou Griffin Bell como procurador-geral dos Estados Unidos. Bell comentou sobre o artigo que escrevi para a Pound Conference de 1976 e estava muito intrigado com o que aprendeu lá. Então, ele criou um gabinete especial do Departamento de Justiça para melhorar a administração da Justiça. Além disso, as lideranças da Pound Conference criaram um grupo de trabalho para analisar as ideias apresentadas e verificar como poderiam ser implementados. Griffin Bell foi o cabeça disso tudo. Mas havia muitas outras influências. A Ordem dos Advogados dos EUA abraçou essa ideia e criou uma comissão especial inicialmente chamada Comissão Especial sobre a Resolução de Litígios Menores. Em 1993, tornou-se Seção de Solução de Controvérsias da Ordem, hoje com mais de 17.000 membros. Assim, a Ordem abraçou a causa. Ela organiza uma conferência nacional a cada primavera que é muito popular na área. Eles criaram um jornal chamado Dispute Resolution Magazine, por isso várias coisas estão acontecendo. Há também uma legislação federal e estadual sobre o assunto. Uma lei interessante que existe em alguns estados é que os advogados têm o dever ético de informar aos clientes sobre as diferentes formas de resolução de disputas para os seus casos. Então, quando se vai a um advogado nestes Estados - como Massachusetts, Colorado e New Jersey, dentre outros - o advogado deve considerar o cenário geral do conflito, como um médico deve fazer em relação a um paciente com alguma doença. : "Meu estômago dói", e que o médico não diz: "Bem, deixe-me pegar meu bisturi e operar". [Os médicos] devem dar opções: "Você pode tomar drogas, você não pode fazer nada sobre isso, você pode ter uma operação". Então, os advogados deveriam estar adotando a mesma medida com as disputas, e que naturalmente leva a uma maior exploração de opções de disputa. E, claro, em seguida, os advogados têm de aprender a agir dessa forma. Esta é uma consequência desse tipo de obrigação".

33 "A task force resulting from the conference was intrigued with Professor Frank Sander's vision of a court that was not simply a courthouse but a dispute resolution center where the grievant, with the aid of a screening clerk, would be directed to the process (or sequence of processes) most appropriate to a particular type of case" (GOLDBERG, Stephen B. et al. dispute resolution: negotiation, mediation, and other processes. 5. ed. New York: Aspen Publishers, 2012. p. 8). Tradução livre: "Uma força-tarefa resultante da conferência ficou intrigada a partir da visão do Professor Frank Sander de um Tribunal que não era simplesmente um 
Tribunal, mas um centro de resolução de conflitos em que o autor, com a ajuda de um funcionário da Justiça (triagem), seria direcionado para o processo (ou sequência de processos) mais adequado(s) para o tipo determinado de caso".

34 Nesse sentido, refere Sander que "we lawyers have been far too single-minded when it comes to dispute resolution ${ }^{\circ}$ We have tended to assume that the courts are the natural and obvious - and only - dispute resolvers. In fact there exists a rich variety of processes which may resolve conflicts far more effectively. Much as the police have been looked for to "solve" racial, school and neighborly disputes, so too have we been making greater and greater demands on the courts to resolve disputes that used to be handled by other institutions of society. Quite obviously, the courts cannot continue to respond effectively to those accelerating demands. It becomes essential therefore to examine other alternatives (CRESPO, Mariana Hernandez; SANDER, Frank. Evolution of the multi- door courthouse. University of St. Thomas Law Journal, Saint Paul, MN, v. 5, n. 3, p. 670, 2008. Disponível em: <http://papers.ssrn. com/ sol3/papers.cfm?abstract_id=1265221>. Acesso em: 28 maio 2014). Tradução livre: "Nós advogados temos uma visão restrita quando se trata de resolução de litígios. Temos a tendência a assumir que os Tribunais são os naturais e óbvios - "resolvedores" de litígios - e só. Na verdade, existe uma grande variedade de processos que podem ser resolvidos de forma mais efetiva. Assim como a polícia tem sido procurada para "resolver" conflitos racial, escolar e as disputas de vizinhança, também percebemos cada vez maiores exigências nos Tribunais para resolver disputas que costumavam ser tratadas por outras instituições da sociedade. Obviamente, os Tribunais não podem continuar a responder eficazmente a essas demandas em crescimento. Torna-se essencial , portanto, examinar outras alternativas".

35 Conforme manifestou Sander, "one of the many things the ABA did is when its Dispute Resolution Committee got some money, it set up a pilot project with multi-door courthouses in three places: Tulsa, Oklahoma; Houston, Texas; and Washington, D.C. And while not all of them have survived, the Washington, D.C. multidoor courthouse [the D.C. Superior Court's Multi-Door Dispute Resolution Division] is now a very active and impressive one. So, this was a useful experiment that showed what to do and what not to do, absolutely" (GABBAY, Daniela Monteiro. Mediação \& Judiciário no Brasil e nos EUA: condições, desafios e limites para a institucionalização da mediação no judiciário. Brasília: Gazeta Jurídica, 2013. p. 128). Tradução livre: "uma das muitas coisas que a Ordem fez, quando o Comitê de Solução de Disputas ganhou algum dinheiro, foi criar um projeto-piloto do sistema multiportas em três lugares: Tulsa, Oklahoma; Houston, Texas; e Washington, DC. Embora nem todos eles tenham sobrevivido, o programa de Washington, DC é agora muito ativo e impressionante. Então, essa foi uma experiência útil que mostrou o que fazer e o que não fazer, absolutamente".

36 GABBAY, Daniela Monteiro. Mediação \& Judiciário no Brasil e nos EUA: condições, desafios e limites para a institucionalização da mediação no judiciário. Brasília: Gazeta Jurídica, 2013.

37 Tradução livre: "Eu tentei olhar para cada processo diferente e visualizar se poderíamos utilizar algum tipo de taxonomia para determinar onde os litígios deveriam ir e quais portas são adequadas para tais disputas".

38 CRESPO, Mariana Hernandez; SANDER, Frank. Evolution of the multi- door courthouse. University of St. Thomas Law Journal, Saint Paul, MN, v. 5, n. 3, p. 670, 2008. Disponível em: < http://papers.ssrn.com/ sol3/ papers.cfm?abstract_id=1265221>. Acesso em: 28 maio 2014.

39 OLIVEIRA, Luthyana Demarchi de; SPENGLER, Fabiana Marion. O fórum múltiplas portas como política pública de acesso à justiça e à pacificação social. Curitiba: Multideia, 2013. p. 27.

40 SIFUENTES, Mônica. Tribunal multiportas. Jus Navigandi, Teresina, v. 11, n. 972, fev. 2006. Disponível em: <http://jus.com.br/artigos/8047/tribunal-multiportas>. Acesso em: 28 maio 2014.

41 BARBOSA, Ivan Machado. Fórum de múltiplas portas: uma proposta de aprimoramento processual. In: AZEVEDO, André Gomma de. Estudos em arbitragem, mediação e negociação. Brasília: Ed. Grupos de Pesquisa, 2003. v. 2. Disponível em: <http://vsites.unb. br/fd/gt/Volume2.pdf> . Acesso em: 23 jun. 2013.

42 SALES, Lilia Maia de Morais; SOUSA, Mariana Almeida de. O Sistema de múltiplas portas e o judiciário brasileiro. Direitos Fundamentais \& Justiça, v. 5, n. 16, p. 204-220, jul./set. 2011.

43 NUNES, Andrine Oliveira; SALES, Lilia Maia de Moraes. A possibilidade do alcance da justiça por meio de mecanismos alternativos associados ao judiciário. 2010. Disponível em: <http:// www.conpedi.org.br/ manaus/arquivos/anais/florianopolis/Inte gra.pdf>. Acesso em: 23 jun. 2013.

44 Consoante Oliveira e Spengler (OLIVEIRA, Luthyana Demarchi de; SPENGLER, Fabiana Marion. O fórum múltiplas portas como política pública de acesso à justiça e à pacificação social. Curitiba: Multideia, 2013. p. 113), "o Fórum Múltiplas Portas é um centro multifacetado cuja premissa é a aplicação do melhor meca- 
nismo, considerando as vantagens e desvantagens do caso específico, no tratamento do conflito. Assim, em vez de apenas uma "porta" que conduz à sala de audiências, esse centro de justiça global tem muitas portas, que podem ser a "negociação", a "conciliação", a "mediação", a "arbitragem", a "avaliação preliminar neutra", dentre outras".

45 OLIVEIRA, Luthyana Demarchi de; SPENGLER, Fabiana Marion. O fórum múltiplas portas como política pública de acesso à justiça e à pacificação social. Curitiba: Multideia, 2013.

46 Nessa ótica, compreende-se que "a combinação variável destes fatores pode levar, em um determinado caso, a diferentes conclusões sobre o processo mais apropriado, e nenhuma suposição taxativa ou conclusão apressada deve ser elaborada de qualquer fator específico" (KEPPEN, Luiz Fernando Tomasi; MARTINS, Nadia Bevilaqua. Introdução à resolução alternativa de conflitos: negociação, mediação, levantamento de fatos, avaliação técnica independente. Curitiba: JM Livraria Jurídica, 2009. p. 102). Adicionam, ainda, Keppen e Martins os seguintes fatores: a) natureza do conflito; b) o tempo do conflito e se há necessidade de uma rápida determinação ou de maior flexibilidade de tempo mais longo; c) o valor da causa; d) a complexidade da causa (de fato e de direito); e) a necessidade ou o anseio de uma decisão judicial, gerando efeitos de precedente; f) os objetivos das partes; $\mathrm{g}$ ) a natureza da relação entre as partes; $\mathrm{h}$ ) a habilidade de negociação das partes sem a assistência de um terceiro; i) os recursos disponíveis para o tratamento do conflito; j) o número de envolvidos; k) se as partes possuem uma relação constante; 1) a necessidade ou desejo de privacidade.

47 FRENCH, Robert. Perspectives on court annexed alternative dispute resolution. 2009. Disponível em: $<$ http://www.hcourt.gov.au/assets/publications/speeches/current-justices/frenchcj/frenchcj27july09.pdf $>$. Acesso em: 28 maio 2014.

48 Tradução livre: "Eu não acredito que o Tribunal seja a forma mais efetiva de realizar esse tipo de tarefa de selecionar."

49 SANDER, Frank. varieties of dispute processing. In: POUND Conference: perspectives on justice in the future. Minnesota: West Publishing Co., 1979. p. 79.

50 SANDER, Frank. Varieties of dispute processing. In: POUND Conference: perspectives on justice in the future. Minnesota: West Publishing Co., 1979. p. 65-87.

51 SANDER, Frank; ROZDEICZER, Lukasz. Matching cases and dispute resolution procedures: detailed analysis leading to a mediation-centered approach. Harvard Negotiation Law Review, v. 11, p. 1-28, 2006.

52 GOLDBERG, Stephen B. et al. Dispute resolution: negotiation, mediation, and other processes. 5. ed. New York: Aspen Publishers, 2012.

53 OLIVEIRA, Luthyana Demarchi de; SPENGLER, Fabiana Marion. O fórum múltiplas portas como política pública de acesso à justiça e à pacificação social. Curitiba: Multideia, 2013.

54 SPENGLER, Fabiana Marion. Da jurisdição à mediação: por uma outra cultura no tratamento de conflitos. Ijuí: Unijuí, 2010.

55 Na concepção de Goldberg et at. (In: GOLDBERG, Stephen B. et al. Dispute resolution: negotiation, mediation, and other processes. 5. ed. New York: Aspen Publishers, 2012. p. 56), "mediation is clearly the preferred procedure when venting is necessary. By providing an informal atmosphere that encourages full participation by the disputants themselves, as well as by their lawyers, and by the presence of a neutral who can control the venting process, mediation can create a safe harbor for the parties to express their views fully. Some venting is possible in the evaluative ADR procedures; however, since their focus is on presenting evidence and argument concerning the rights of the parties, they are less hospitable to expressions of feelings". Tradução livre: "a mediação é claramente o procedimento preferencial quando é necessária uma abertura. Ao fornecer um ambiente informal que incentiva a plena participação das partes, bem como por seus advogados, e a presença de um neutro que pode controlar o processo de abertura dos disputantes, a mediação pode criar um porto seguro para que as partes expressem completamente seus pontos de vista. Alguma abertura é possível nos procedimentos de avaliação de ADR, no entanto, uma vez que seu foco está em apresentar provas e argumentos sobre os direitos das partes, eles são menos hospitaleiros para expressar sentimentos".

56 Spengler (In: SPENGLER, Fabiana Marion. Fundamentos políticas da mediação comunitária. Ijuí: editora Unijuí, 2012. p. 94) refere que "de fato, o principal desafio que a mediação enfrenta não é o de gerar relações calorosas e aconchegantes, sociedades isentas de litígio ou uma ordem de mundo harmoniosa. Ao invés disso, considerando-se a natureza endêmica do conflito, talvez o seu principal desafio seja encontrar mecanismo que possibilitem uma convivência comunicativamente pacífica". 
57 SPENGLER, Fabiana Marion. Fundamentos políticas da mediação comunitária. Ijuí: editora Unijuí, 2012.

58 Por essa razão, "escolher a mediação é, para cada um dos dois adversários, compreender que o desenvolvimento da sua hostilidade só lhes pode ser prejudicial e que têm todo o interesse em tentar encontrar, por meio de um acordo amigável, uma saída positiva para o conflito que os opõe. [...] A maior parte das vezes, as decisões da justiça cortam o nó de um conflito, designando um ganhador e outro perdedor - um ganha o seu processo o outro o perde - e as duas partes saem do tribunal mais adversárias do que nunca. A mediação não se preocupa tanto em julgar um facto passado - que é o que faz a instituição judicial - como em apoiar-se nele para o ultrapassar e permitir que os adversários de ontem inventem um futuro liberto do peso de seu passado" (MULLER, Jean - Marie. Não-violência na educação. Tradução de Tônia Van Acker. São Paulo: Palas Athenas, 2006. p. 171).

59 MULLER, Jean - Marie. Não-violência na educação. Tradução de Tônia Van Acker. São Paulo: Palas Athenas, 2006.

60 CALMON, Petrônio. Fundamentos da mediação e da conciliação. Brasília: Gazeta Jurídica, 2015. p. 144.

61 BARBOSA, Ivan Machado. Fórum de múltiplas portas: uma proposta de aprimoramento processual. In: AZEVEDO, André Gomma de. Estudos em arbitragem, mediação e negociação. Brasília: Ed. Grupos de Pesquisa, 2003. v. 2. Disponível em: <http://vsites.unb. br/fd/gt/Volume2.pdf>. Acesso em: 23 jun. 2013.

62 BARBOSA, Ivan Machado. Fórum de múltiplas portas: uma proposta de aprimoramento processual. In: AZEVEDO, André Gomma de. Estudos em arbitragem, mediação e negociação. Brasília: Ed. Grupos de Pesquisa, 2003. v. 2. Disponível em: <http://vsites.unb. br/fd/gt/Volume2.pdf>. Acesso em: 23 jun. 2013.

63 OLIVEIRA, Luthyana Demarchi de; SPENGLER, Fabiana Marion. O fórum múltiplas portas como política pública de acesso à justiça e à pacificação social. Curitiba: Multidéia, 2013.

64 MORAIS, Jose Luis Bolzan de; SPENGLER, Fabiana Marion. Mediação e arbitragem: alternativas à jurisdição! Porto Alegre: Livraria do Advogado, 2012.

65 GOLDBERG, Stephen B. et al. Dispute resolution: negotiation, mediation, and other processes. 5. ed. New York: Aspen Publishers, 2012.

66 OLIVEIRA, Luthyana Demarchi de; SPENGLER, Fabiana Marion. O fórum múltiplas portas como política pública de acesso à justiça e à pacificação social. Curitiba: Multidéia, 2013.

67 CALMON, Petrônio. Fundamentos da mediação e da conciliação. Brasília: Gazeta Jurídica, 2015.

68 BARBOSA, Ivan Machado. Fórum de múltiplas portas: uma proposta de aprimoramento processual. In: AZEVEDO, André Gomma de. Estudos em arbitragem, mediação e negociação. Brasília: Ed. Grupos de Pesquisa, 2003. v. 2. Disponível em: <http://vsites.unb. br/fd/gt/Volume2.pdf>. Acesso em: 23 jun. 2013.

69 GOLDBERG, Stephen B et al. Dispute resolution: negotiation, mediation, and other processes. 5. ed. New York: Aspen Publishers, 2012.

70 Nesse sentido, Calmon (In: CALMON, Petrônio. Fundamentos da mediação e da conciliação. Brasília: Gazeta Jurídica, 2015. p. 96) refere que "o número de jurados é reduzido e é possível até dividir os jurados em dois júris distintos, a fim de proporcionar que sejam colhidas duas opiniões distintas, que podem ou não coincidir."

71 OLIVEIRA, Luthyana Demarchi de; SPENGLER, Fabiana Marion. O fórum múltiplas portas como política pública de acesso à justiça e à pacificação social. Curitiba: Multidéia, 2013. p. 103.

72 Tradução livre: "para aqueles casos novos ou não usuais em que o veredicto do júri é difícil de prever e a dificuldade é alcançar um acordo."

73 GOLDBERG, Stephen B. et al. Dispute resolution: negotiation, mediation, and other processes. 5. ed. New York: Aspen Publishers, 2012. p. 435.

74 Compreende-se que "the concept underlying the minitrial is that it provides each business executive with a crash course in the merits of the dispute - a brief but firsthand view of the best case that can be put forward by the attorneys for both sides, supplemented, if necessary, by the views of a neutral. Armed with this information, as well as their knowledge of the business relationships of the parties, the executives are equipped to negotiate a resolution of their dispute that makes business sense" (GOLDBERG, Stephen B. et al. Dispute resolution: negotiation, mediation, and other processes. 5. ed. New York: Aspen Publishers, 2012. p. 431). Tradução livre: "o conceito subjacente ao minitrial é que ele fornece a cada executivo com um curso intensivo sobre o mérito da controvérsia - uma visão breve, mas em primeira mão do melhor dos casos que podem ser invocados pelos advogados de ambos os lados, acrescentando-se, se necessário, o ponto de vista do terceiro neutro. Armados 
com esta informação, bem como os seus conhecimentos sobre as relações comerciais das partes, os executivos estão preparados para negociar uma resolução do seu conflito que faz sentido para os negócios."

75 CALMON, Petrônio. Fundamentos da mediação e da conciliação. Brasília: Gazeta Jurídica, 2015.

76 Para Goldberg, Sander, Rogers e Cole (In: GOLDBERG, Stephen B. et al. Dispute resolution: negotiation, mediation, and other processes. 5. ed. New York: Aspen Publishers, 2012. p. 423), "the central advantage of med-arb over "pure" mediation followed if necessary by "pure" arbitration, in which different neutrals serve as mediator and arbitrator, is said to be that of efficiency." Tradução livre: "a principal vantagem da med-arb diante da mediação "pura" seguida da arbitragem "pura", na qual diferentes neutros são mediador e árbitro, é a eficiência."

77 CALMON, Petrônio. Fundamentos da mediação e da conciliação. Brasília: Gazeta Jurídica, 2015. p. 93.

78 Adiciona-se que esses métodos "têm em comum o fato de reunirem dois mecanismos privados e espontâneos, que podem ser realizados sob orientação coordenada, mas deve-se atentar à necessidade de separar as funções do mediador e do árbitro, para evitar qualquer influência ou quebra do sigilo, características intrínsecas à mediação. No sistema med/arb, caso o mediador seja sucessivamente o árbitro, ele já terá ouvido as partes em aspectos sensíveis, contaminando sua imparcialidade. Já no sistema arb/med, apesar de o árbitro já ter prolatado a sentença, não tendo conhecido qualquer fato reservado das partes, seu conhecimento da decisão, que ele próprio elaborou, o fará agir sob essa influência, contaminando a condução das tratativas para o acordo" (CALMON, Petrônio. Fundamentos da mediação e da conciliação. Brasília: Gazeta Jurídica, 2015. p. 93-94).

79 OLIVEIRA, Luthyana Demarchi de; SPENGLER, Fabiana Marion. O fórum múltiplas portas como política pública de acesso à justiça e à pacificação social. Curitiba: Multideia, 2013. p. 103.

80 Como referem Goldberg, Sander, Rogers e Cole (In: GOLDBERG, Stephen B. et al. Dispute resolution: negotiation, mediation, and other processes. 5. ed. New York: Aspen Publishers, 2012. p. 436), "the person's job is to help resolve work-related disputed through informal counseling, mediation, or, more rarely, investigation and recommendations to management". Ademais, "ombudspeople attempt to assure employees not only that they are neutral but that they will keep all communications confidential and help to protect complaining employees from reprisals". Tradução livre: "o trabalho é ajudar a resolver disputas relacionadas ao trabalho por meio de aconselhamento informal, mediação e, mais raramente, investigação e encaminhamento à gerência". / "o ouvidor busca assegurar aos empregados não somente que ele é neutro, mas que manterá toda a comunicação confidencial e protegerá as reclamações dos empregados a salvo de represálias."

81 CALMON, Petrônio. Fundamentos da mediação e da conciliação. Brasília: Gazeta Jurídica, 2015. p. 93.

82 Keppen e Martins (In: KEPPEN, Luiz Fernando Tomasi; MARTINS, Nadia Bevilaqua. Introdução à resolução alternativa de conflitos: negociação, mediação, levantamento de fatos, avaliação técnica independente. Curitiba: JM Livraria Jurídica, 2009. p. 85) indicam, também, como porta, o levantamento de dados (fact-finding), o qual "consiste em uma forma geral de investigação acurada sobre os fatos geradores do conflito, efetuada por uma terceira pessoa imparcial, que poderá apresentar relatório e fazer um aconselhamento sobre os termos do acordo. Esse método pode tomar muitas formas puras ou combinadas [...]”, como a avaliação técnica independente ou o mini júri. Adiciona, igualmente, o método baseball (last-offer arbitration) ou arbitragem vinculada, cuja ideia "é uma combinação de negociação e arbitragem. As partes negociam o ponto de impasse e então submetem alternativas ao árbitro, cuja responsabilidade única é selecionar a oferta de uma ou de outra parte" (p. 98-99). A seu turno, Calmon (In: CALMON, Petrônio. Fundamentos da mediação e da conciliação. Brasília: Gazeta Jurídica, 2015. p. 95) apresenta o confidential listener ou ouvinte neutro confidencial, ou seja, um terceiro imparcial a quem as partes apresentam a sua proposta de oferta final. Desse modo, "sem revelar o conteúdo de cada proposta à parte contrária, o ouvinte neutro lhe informa se, diante dessas propostas, há qualquer possibilidade de se chegar a um acordo ou se, ao contrário, suas posições são demasiadamente distantes. Em geral, os limites da oferta são fixados anteriormente, como também os critérios para resolver eventual diferença. Se as ofertas são apresentadas fora dos limites, o ouvinte pode tentar mediar um acordo. O ouvinte não precisa explicar os critérios de sua conclusão e deve manter a mais rigorosa reserva sobre o conteúdo de cada proposta, a menos que as partes o dispensem dessa obrigação."

83 SALES, Lilia Maia de Morais; SOUSA, Mariana Almeida de. O sistema de múltiplas portas e o judiciário brasileiro. Direitos Fundamentais \& Justiça, v. 5, n. 16, p. 204-220, jul./set. 2011.

84 MORAIS, Jose Luis Bolzan de; SPENGLER, Fabiana Marion. Mediação e arbitragem: alternativas à jurisdição! Porto Alegre: Livraria do Advogado, 2012. 
85 OLIVEIRA, Luthyana Demarchi de; SPENGLER, Fabiana Marion. O fórum múltiplas portas como política pública de acesso à justiça e à pacificação social. Curitiba: Multideia, 2013. p. 109.

86 Gabbay (In: GABBAY, Daniela Monteiro. Mediação \& Judiciário no Brasil e nos EUA: condições, desafios e limites para a institucionalização da mediação no judiciário. Brasília: Gazeta Jurídica, 2013. p. 151-176) realizou uma pesquisa empírica em quatro programas multiportas dos Estados de Flórida, Ohio, Connecticut e Maine. Após a coleta de dados, afirma que "os pontos considerados como centrais para o sucesso dos programas de mediação foram: (i) forte suporte do Judiciário aos programas de solução de conflitos anexos à Corte; (ii) uma clara definição das formas e opções de soluções de conflitos; (iii) um quadro de funcionários da Corte altamente experiente e qualificado para implementar, monitorar e avaliar os programas; (iv) um processo de educação dos advogados e das partes sobre as opções de solução de conflitos, combinado a critérios ou a métodos para triagem dos casos que são direcionados aos processos de solução de conflitos; (v) requerimento aos litigantes para debaterem as escolhas de solução de conflitos e o processo da Corte de triagem e encaminhamento dos casos; (vi) escolha das partes sobre qual processo de solução de conflitos selecionar para cada caso específico; (vii) provedores e servidores, internos e externos ao Judiciário, de qualidade e sistemas de manutenção desta qualidade e integridade; (viii) plena integração do programa de solução de disputas com o gerenciamento dos casos e um agendamento realista do julgamento."

87 Assim, "the programs were designed to function as an integral part of the administration of the courts and to divert cases to the most appropriate 'door' using screening criteria suggested by Sander and further developed in each project. Unlike individual court-annexed dispute resolution programs, the multi-door model provides a coordinated approach to dispute resolution with intake and referral operating under one centralized program, rather than independently. Flexibility, which enables each system to adapt the multi-door concept, has been a hallmark of these programs" (FRENCH, Robert. Perspectives on court annexed alternative dispute resolution. 2009. Disponível em: <http://www.hcourt.gov.au/assets/publications/speeches/current-justices/ frenchcj/frenchcj27july09.pdf>. Acesso em: 28 maio 2014. p. 5-6). Tradução livre: "Os programas foram concebidos para funcionar como parte integrante da administração dos Tribunais e para encaminhar casos à "porta" mais apropriada, usando critérios de triagem sugeridos por Sander e desenvolvidos em cada projeto. Ao contrário dos programas individuais de resolução de litígios, o modelo do Múltiplas Portas fornece uma abordagem coordenada à resolução de litígios com a ingestão e o encaminhamento, operando sob um programa centralizado ao invés de forma independente. Flexibilidade a qual permite que a adaptação de cada sistema ao conceito Múltiplas Portas é uma marca desse programa."

CONSENSUAL JUSTICE IN THE OPEN-DOOR COURTHOUSE MODEL AND THE NORTH-AMERICAN POLICY FOR THE TREATMENT OF CONFLICTS: CONTRIBUTIONS TO THE BRAZILIAN MODEL

\begin{abstract}
This work has as its subject consensual justice and the conflict treatment and is focused on studying the North American Multi-Door Courthouse model and its possible contributions to the Brazilian Public Policy for the Treatment of Conflicts - Resolution number 125 from November 29th 2010 of the Brazilian National Justice Council. This study, from a hypothetical-deductive approach and bibliographical research, deserves a deepened analysis due to the difficulties faced by the traditional
\end{abstract}


methods adopted by the Judiciary to satisfactorily answer all conflicts, and the obstacles the alternative methods of dispute resolution face in Brazil in order to be solidified as a conflict treatment method. On the other hand, it indicates the experience in the United States, where the alternative methods have been studied since the 1920s, recognized a dichotomous approach, with which the parties themselves can build their responses according to their needs, interests and mutual relationship. So, considering the characteristics of the conflict, it presents the most suitable method for their conflict, ensuring the satisfaction of those involved. In this sense, it guarantees access to the justice in wide sense and strengthens social participation of the person, thus fomenting a culture of peace, of alterity and of treating of conflict in a qualitative way, more suited to the characteristics of each individual person and conflict type.

Keywords: Treatment of conflict. Multi-Door Courthouse. Consensual Justice. Culture of Peace.

Submetido: 1 fev. 2017

Aprovado: 10 maio 2017 